\title{
The Syndrome of Food-Cobalamin Malabsorption: A Personal View in a Perspective of Clinical Practice
}

Emanuel Andres ${ }^{1}$, Khalid Serraj ${ }^{1}$, Mustapha Mecili' ${ }^{1}$, Georges Kaltenbach ${ }^{2}$ and Thomas Vogel ${ }^{2}$

${ }^{1}$ Service Médecine Interne, Diabète et Maladies métaboliques, Clinique Médicale B, Hôpitaux Universitaires de Strasbourg, Strasbourg, France ${ }^{2}$ Service Médecine Interne et Gériatrie, Hôpital de la Robertsau, Hôpitaux Universitaires de Strasbourg, Strasbourg, France

\begin{abstract}
Summary
This article presents recent findings on cobalamin deficiencies due to food-cobalamin malabsorption or nondissociation of vitamin B12 from its carrier proteins syndrome. These findings might be of interest to medical practitioners. This disorder, for which a definitive consensus on the criteria for diagnosis is not yet available, is the leading cause of cobalamin deficiency in the elderly. In practice, food-cobalamin malabsorption is a diagnosis of exclusion, and requires the deductive elimination of all other causes of cobalamin deficiencies, particularly pernicious anaemia. The causes or associated disorders of food-cobalamin malabsorption are multiple and include gastric pathologies, Helicobacter pylori infections and certain drugs (biguanides and proton pump inhibitors). Depending on the disease aetiology, treatment of food-cobalamin malabsorption involves oral supplementation of doses lower than those required for pernicious anaemia.
\end{abstract}

Keywords: Vitamin B12; Cobalamin; Cobalamin deficiency; Foodcobalamin malabsorption; Oral cobalamin therapy

\section{Introduction}

Until the 1990s, the most common recognised cause of cobalamin deficiency in adults was pernicious anaemia [1]. Thanks to progress made during the last 10-20 years in the understanding of vitamin B12 metabolism, "new" physiopathological concepts have emerged or recognized, including a controversial medical concept entitled food-cobalamin malabsorption (FCM) in Anglo-Saxon literature, also known as "syndrome de non-dissociation de la vitamine B12 de ces protéines porteuses" in French literature [2,3]. This clinical condition is the leading cause of cobalamin deficiency in a number of recently published series, especially in elderly patients [4]. It's to note that currently, FCM continues to be intensively studied and discussed because of the controversial nature of the disorder [3,5].

As this syndrome has been well described for the first time only quite recently (in a complete exhaustive review [4], we sought to detail the clinical, physiopathological and therapeutic particularities of the FCM syndrome, with a special focus on the works on our group (CARE B12) and in a perspective of clinical practice.

\section{Definition and physiopathological rationale}

Vitamin B12, or cobalamin, is found exclusively in animal source foods, and daily intake requirements range from 2 to $5 \mu \mathrm{g}$ [6]. Ingested cobalamin is bound to food proteins and salivary and gastric glycoproteins, such as haptocorrin, in the stomach [7]. The dissociation of vitamin B12 from its carrier proteins and its release as unbound cobalamin are essential prerequisites for its binding to intrinsic factor and its intestinal absorption via the cubilin receptor (Figure 1) (an exhaustive and comprehensive review of the cobalamin metabolism is available in reference [7]. FCM is a medical condition that is characterized by the inability to release cobalamin from its carrier proteins [4].

The FCM syndrome was first described by by Doscherholmen in 1973 [8] and well characterized by Carmel and Dawson in the 1990s $[4,9]$. In some cobalamin-deficient patients, these authors observed conflicting results when employing a modified Schilling test, which uses radioactive cobalamin bound to altered animal proteins (e.g., egg yolk, chicken, salmon), and the normal Schilling, which uses free

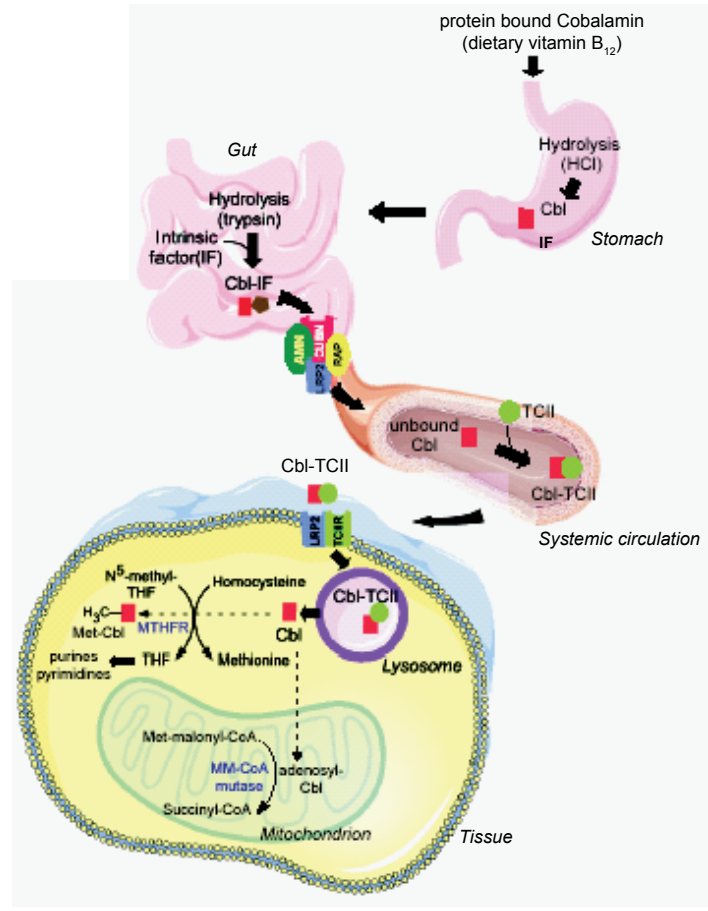

Figure 1: Cobalamin metabolism.

*Corresponding author: Prof. E. Andrès, Service de Médecine Interne, Diabète et Maladies Métaboliques, Clinique Médicale B, Hôpital Civil - Hôpitaux Universitaires de Strasbourg, 1 porte de l'Hôpital, 67091 Strasbourg Cedex, France, Tel: (33) (0)3-88-11-50-66; Fax: 88-11-62-62; E-mail: emmanuel.andres@chru-strasbourg.fr

Received June 02, 2011; Accepted July 20, 2011; Published July 29, 2011

Citation: Andres E, Serraj K, Mecili M, Kaltenbach G, Vogel T (2010) The Syndrome of Food-Cobalamin Malabsorption: A Personal View in a Perspective of Clinical Practice. J Blood Disord Transfus 2:108. doi:10.4172/2155-9864.1000108

Copyright: (C) 2011 Andres E. This is an open-access article distributed under the terms of the Creative Commons Attribution License, which permits unrestricted use, distribution, and reproduction in any medium, provided the original author and source are credited. 
radioactive vitamin B12 [unbound] [8].

Today, the syndrome refers to all vitamin B12 deficiencies that are related to pre-absorption steps [4]. Table 1 summarizes the empirical criteria we have previously proposed to retain the diagnosis of foodcobalamin malabsorption [10]. This table includes the Schilling tests (standard and modified), which are the gold standard to establish the diagnosis of FCM [4]. However in a diagnosis perspective, it's important to note that these tests are not currently available in clinical practice. It's also important to keep in mind that these criteria are not validated in evidence-based medicine approach.

\section{Epidemiology and associated causes}

In the Framingham cohort, the prevalence of cobalamin deficiency was estimated between $12 \%$ and $20 \%$ [11]. Some authors reported a prevalence of $40 \%$ among elderly patients living in institutions $[1,12]$. According to our own experience, the prevalence of cobalamin deficiency (serum levels of cobalamin $<200 \mathrm{pg} / \mathrm{mL}$ and total homocystein $>13 \mu \mathrm{mol} / \mathrm{L}$ ) among hospitalized patients for any reason approaches 5\%, with FCM accounting for $50 \%$ to $60 \%$ of cases (with the criteria of FCM reported in Table 1) [1,6]. Figure 2 shows the distribution of cobalamin aetiologies in 160 patients (median age $>69$ years) followed in an internal medicine department of a tertiary referral university hospital centre [1].

It should be noted, however, that FCM was not mentioned in a number of recently published series on cobalamin deficiencies $[13,14]$, which may be because the clinical entity was not recognized or not scientifically accepted as a true entity. In fact until 1990's, FCM is an important cause of B12 deficiency that previously has not been appreciated by the general medical community. The scepticism came mainly from the fact that FCM can be diagnosed reliably without actually measuring absorption status. The scepticism came also from the fact that initially FCM was reported to be responsible for a majority of subtle cobalamin deficiencies (with no clinical significance) [15].

As illustrated in Table 1, several causes or "associated" disorders of cobalamin malabsorption have been reported, the most common being age, atrophic gastritis, gastric disease associated with $H$. pylori infection, and the intake of proton pump inhibitors, H2-receptor antagonists, or metformin $[4,10]$. For age, various studies using direct absorption testing have shown that most elderly persons do not have FCM, and their rates of FCM are only slightly higher than in younger adults. According to some authors, advanced age is a physiological condition that is frequently associated with non-dissociation [12]. Our

Diagnosis criteria cobalamin deficiency related to FCM syndrome:

- Low serum cobalamin levels (<200 pg/ml)

- Normal "standard" Schilling test (using free cyanocobalamin labelled with cobalt-57) or abnormal "modified" Schilling test (using protein-bound radioactive cobalamin) $\ddagger$

- No dietary cobalamin deficiency (intake > at least at 2.5 to $5 \mu \mathrm{g}$ per day) Presence of a predisposing or associated disorders:

Atrophic gastritis, chronic $H$. pylori infection, gastrectomy, gastric by-pass

- Exocrine pancreatic insufficiency (mainly related to alcohol abuse)

- Chronic alcohol abuse

- Intake of antacids (H2-receptor antagonists or proton pump inhibitors) or biguanides (metformin)

- Microbial overgrowth, AIDS

Sjögren's syndrome, scleroderma

- "Idiopathic" (related to age?)

‡: The "modified" Schilling test uses food-bound cobalamin (e.g. egg, chicken and fish proteins...); today, these test are not available in clinical routine.

Table 1: Characteristics of food-cobalamin malabsorption (FCM) syndrome according to Andrès et al. $[1,6]$.

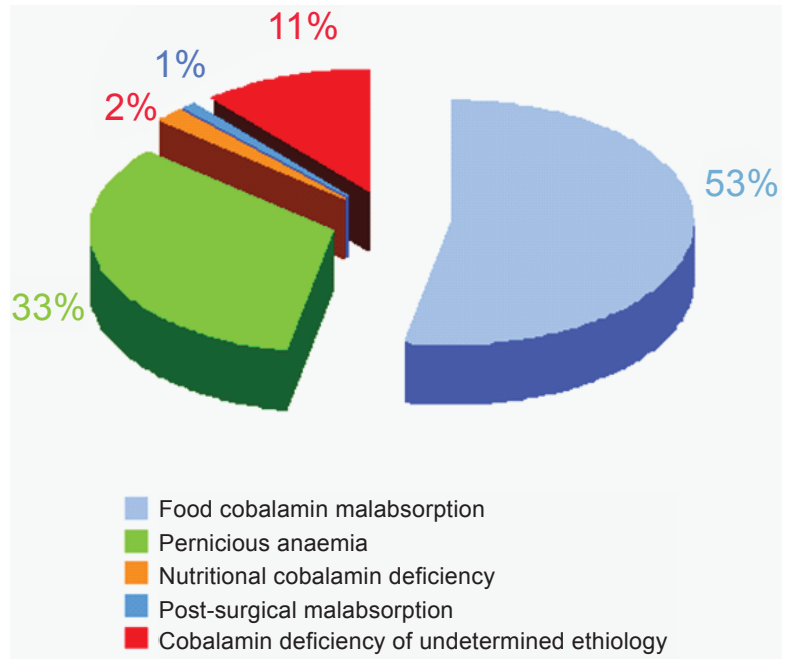

Figure 2: Distribution of various cobalamin deficiency aetiologies in adults ( $n=160$ patients) [2].

group have documented that FCM is the leading cause of cobalamin deficiency in elderly patients [2]. For H. pylori infection, it's to note that studies employing direct absorption testing, while showing an increased association between FCM and H. pylori, noted that most infected people have normal absorption and many people with FCM do not have infection. Nevertheless in an American study including 202 subjects, Latino-American or Afro-American race, advanced age, and H. pylori infection were shown to be independent risk factors for FCM. Some studies revealed a female preponderance, though this still needs to be confirmed [16].

\section{Clinical manifestations}

The primary clinical manifestations of FCM-related cobalamin deficiency are not very different from those of cobalamin deficiencies associated with other causes $[4,17]$. In rooutine clinical practice, the clinical signs encountered are often due to underlying predilection factors such as old age rather than to the non-dissociation itself. However, it should be emphasized that Carmel first believed that FCM was associated with moderate cobalamin deficiency, leading to only subtle clinical symptoms ("subtle cobalamin deficiency") [4]. Our recent published data contradicts this assertion [18], as illustrated in Table 2 [10]. Nevertheless it's important to keep in mind in general population that only a very small percentage of patients with FCM habitually and actually progress to overt clinical B12 deficiency.

The classic haematological abnormalities encountered include unregenerative macrocytary anaemia and other less common, though more severe, haematological abnormalities: intramedullar haemolysis, thrombopenic purpura, myelodysplasia, medullar aplasia, early-stage pseudo-leukosis, or pseudo-thrombotic microangiopathy [18-21]. Of note, a comparative trial showed that the frequency of severe anaemia was lower and the severity of macrocytosis less marked in patients presenting with FCM as compared to those affected by pernicious anaemia [22].

Neuropsychiatric abnormalities are also common clinical manifestations that often precede haematological abnormalities, and may occur even if haematological abnormalities do not develop (Table 2). Subacute combined degeneration of the spinal cord, peripheral 


\begin{tabular}{|l|l|}
\hline Mean age & $76 \pm 8$ years \\
\hline Sex ratio (women/men) & 2 \\
\hline Main clinical manifestations & \\
\hline • Sensitive polyneuropathy & $45 \%$ \\
\hline • Cognitive disorders & $23 \%$ \\
\hline - Asthenia & $21 \%$ \\
\hline Main biological manifestations & \\
\hline - Macrocytosis & $53 \%$ \\
\hline - Anaemia & $21 \%$ \\
\hline - Leucopenia & $11 \%$ \\
\hline - Thrombocytopenia & $9 \%$ \\
\hline - Pancytopenia & $6.5 \%$ \\
\hline
\end{tabular}

Table 2: Profile of 92 elderly patients with cobalamin deficiency secondary to foodcobalamin malabsorption syndrome [10].

neuropathies, or cognitive dysfunctions are frequent manifestations $[3,18,23]$. Generally, improvement in neuropsychiatric disorders is less marked if the symptoms have been present for a long time, hence the necessity for early diagnosis and prompt cobalamin supplementation $[4,5]$. However, the absence of any improvement following supplementation should provoke the clinician to question the relation between the reported symptoms and vitamin cobalamin deficiency. Such symptoms could have been owing to causes other than cobalamin deficiency, particularly in elderly subjects with multiple co-morbidities [18].

Besides the aforementioned manifestations, those related to the aetiology of malabsorption should also be considered.

\section{Positive and aetiological diagnosis}

In theory, only the association of a normal standard Schilling test and an abnormal modified Schilling test will permit a positive diagnosis of FCM [4]. We have previously proposed not consensually accepted criteria to establish the diagnosis (Table 1) [10]. For several authors, the controversy derives from the unproven claim that FCM can be diagnosed reliably without actually measuring absorption status. For these authors, such an idiosyncratic concept is scientifically acceptable only if the criteria were subjected to rigorous comparison against the 'gold standard' of direct tests of food cobalamin absorption testing ("validated" criteria). To date, this was unfortunately not done (exposing several recent published studies to some scepticism). Nevertheless, our criteria permit selection of a homogenous profile of patients with cobalamin deficiency not related to nutritional deficiency, pernicious anaemia and malabsorption $[10,18]$, patients that may benefice from oral cobalamin therapy.

In practice, due to the current non-availability of the Schilling tests, FCM currently remains a diagnosis of exclusion [2]. Once cobalamin deficiency has been documented, the first step towards aetiological diagnosis is to rule out insufficient nutritional cobalamin intake or intestinal malabsorption by taking a thorough food anamnesis and searching for other clinical or biological signs of malnutrition or malabsorption $[2,4]$. The next step aims to eliminate pernicious anaemia [24], the main differential diagnosis of FCM, by searching for anti-intrinsic factor antibodies and anti-gastric parietal cell antibodies and performing a gastroscopy with systematic biopsies so as to detect auto-immune atrophic funditis [25]. It's important to note that this "deductive elimination" FCM diagnosis process has not been validated in an evidence based medicine approach but may be of interest in routine.

Finally, an explanation of the non-dissociation should be sought and the exact causes and/or associated disorders investigated. Nondissociation syndrome requires exploration of certain aetiologies or associated disorders, which may be or must be treated in addition to vitamin substitution (in some cases, with a complete and definitive cure of the cobalamin deficiency [see below]. In our experience, FCM is mainly due to iatrogenic causes such as proton pump blockers, H2blockers, and biguanides, as well as alcohol abuse, gastric diseases, chronic pancreatic insufficiency, and chronic infections such as $H$. pylori $[26,27]$. Table 1 shows the complete list of FCM causes or associated disorders that must be search $[1,8]$. It's to note that in most cases, FCM remains idiopathic.

\section{Treatment}

When FCM was identified as a major cause of cobalamin deficiency, the usefulness of oral supplementation in managing cobalamin deficiencies, which had previously been treated only by the parental route, was questioned and confirmed [28,29]. It should be noted from a practical point of view that only $1 \%$ of crystallin vitamin B12 (free) orally administered is absorbed by a passive diffusion mechanism (independently of intrinsic factor and cubilin) [7,28].

Since 1995, numerous clinical trials confirmed the non-inferiority of the oral route as compared to the parental route in the treatment of FCM, as evidenced by a normalisation of haematological abnormalities and regression of clinical symptoms, particularly neuropsychiatric manifestations, in the majority of patients $[28,29]$. It's important to keep in mind that early intervention is important to prevent permanent neurological damage. We have recently published an exhaustive review of the efficacy of oral cobalamin therapy in reference [29]. Table 3 summarizes the results of various not blinded, placebo-controlled trials that we conducted with oral cyanocobalamin in the context of FCM management [30-32]. All of the patients who were treated orally corrected their vitamin B12 levels and at least $80 \%$ corrected their hematological abnormalities. Moreover, half of the patients experienced a clinical improvement on oral treatment [29-32,34]. It is to note that the effect of oral cobalamin treatment in patients presenting with severe neurological manifestations has not yet been adequately documented [29]. According to our experience and other published series (placebocontrolled trials), oral cyanocobalamin was also effective in pernicious anaemia [33-36]. Sublingual and nasal cyanocobalamin administrations were also tested in vitamin B12 deficient patients, regardless of aetiology, with satisfactory results $[37,38]$.

To ensure rapid correction of cobalamin deficiency and regression of clinical manifestations (particularly neuropsychiatric symptoms), clinical studies revealed that an initial oral daily dose of $1000 \mu \mathrm{g}$ cyanocobalamin during at least 1 week was necessary, followed by 1000 to $2000 \mu \mathrm{g}$ per week during 1 month, then $1000 \mu \mathrm{g}$ once to twice per month $[28,29]$. However, this dosage regimen has been continuously and markedly decreased in these last years (see or current recommendations in [29], perhaps because absorption by the intrinsic factor-cubilin complex is maintained (for free not-bound cobalamin), and adds to the cobalamin portion that is absorbed by passive diffusion. In one of the studies conducted by the Strasbourg team, patients having received 250 to $500 \mu \mathrm{g} /$ day exhibited favourable biological and clinical responses that were similar in size to those observed with the full dose [31]. A similar observation was later made in several other clinical trials using still lower dose levels $[34,36,39]$. In 2007, a robust trial demonstrated than an optimal efficacy was obtained with dose levels not exceeding 


\begin{tabular}{|c|c|c|c|}
\hline $\begin{array}{c}\text { Type of study-number of subjects-study } \\
\text { population }\end{array}$ & Therapeutic modalities & Main results & \\
\hline $\begin{array}{l}\text { - Open prospective study } \\
\text { - } \mathrm{n}=10 \text { subjects } \\
\text { - Cobalamin deficiency related to food-cobalami } \\
\text { malabsorption }\end{array}$ & $\begin{array}{l}\text { Oral cyanocobalamin: } 650 \mu \mathrm{g} / \text { day during } 3 \\
\text { months }\end{array}$ & $\begin{array}{l}\text { - Normalisation of serum cobalamin levels in } 80 \% \text { of subjects } \\
\text { - Significant } 1.9 \mathrm{~g} / \mathrm{dl} \text { increase in } \mathrm{Hb} \text { and significant } 7.8 \mathrm{fl} \text { de crease } \\
\text { in ECV } \\
\text { - Improvement of clinical abnormalities in } 20 \% \text { of subjects }\end{array}$ & [31] \\
\hline $\begin{array}{l}\text { - Open prospective study } \\
\text { - } \mathrm{n}=30 \\
\text { - Cobalamin deficiency related to food-cobala- } \\
\text { min malabsorption }\end{array}$ & $\begin{array}{l}\text { Oral cyanocobalamin: } 250 \text { to } 1000 \mu \mathrm{g} / \text { day } \\
\text { during } 1 \text { month }\end{array}$ & $\begin{array}{l}\text { - Normalisation of serum cobalamin levels in } 87 \% \text { of the subjects } \\
\text { - Significant } 0.6 \mathrm{~g} / \mathrm{dl} \text { increase in } \mathrm{Hb} \text { and significant } 3 \mathrm{fl} \text { decrease } \\
\text { in ECV; normalisation of } \mathrm{Hb} \text { and ECV in } 54 \% \text { and } 100 \% \text { of the } \\
\text { subjects, respectively } \\
\text { - Dose effect (dose }>500 \mathrm{\mu g} / \text { day more effective) }\end{array}$ & [30] \\
\hline $\begin{array}{l}\text { - Open prospective study } \\
\text { - } \mathrm{n}=30 \\
\text { - Cobalamin deficiency related to food-cobala- } \\
\text { min malabsorption }\end{array}$ & $\begin{array}{l}\text { Oral cyanocobalamin: } 125 \text { to } 1000 \mu \mathrm{g} / \text { day } \\
\text { during } 1 \text { week }\end{array}$ & $\begin{array}{l}\text { - Normalisation of serum cobalamin levels in all patients treated } \\
\text { with }>250 \mu \mathrm{g} / \mathrm{day} \\
\text { - Dose effect (dose }>500 \mu \mathrm{g} / \text { day more effective) }\end{array}$ & [32] \\
\hline $\begin{array}{l}\text { - Retrospective study } \\
\text { - } n=31 \\
\text { - Cobalamin deficiency related to food-cobal- } \\
\text { amin malabsorption }(n=20) \text { and pernicious } \\
\text { anaemia }(n=10)\end{array}$ & $\begin{array}{l}\text { Oral cyanocobalamin: } 125 \text { to } 1000 \mu \mathrm{g} / \text { day } \\
\text { during at least } 3 \text { month }\end{array}$ & $\begin{array}{l}\text { - Significant } 161.6 \mathrm{pg} / \mathrm{mL} \text { increase of serum cobalamin levels in } \\
\text { food-cobalamin group and } 136.7 \mathrm{pg} / \mathrm{mL} \text { in pernicious anaemia } \\
\text { - Improvement of haematological abnormalities in } 90.1 \% \text { of sub- } \\
\text { jects }\end{array}$ & [34] \\
\hline
\end{tabular}

$\mathrm{Hb}$ : haemoglobin, ECV: erythrocyte cell volume

Table 3: Experience on oral food-cobalamin therapy for food-cobalamin malabsorption in the Strasbourg University Hospital, France.

$80 \mu \mathrm{g} /$ day but administered for an additional 30 days [39]. Thus for practical issues, we now recommend cyanocobalamin doses of 125 to $1000 \mu \mathrm{g} /$ day for FCM treatment as loading doses and 125 to $500 \mu \mathrm{g} /$ day as maintenance doses [29,34]. However, the recommendation of oral vitamin B12 as a definitive treatment has not yet been fully validated in current clinical practice. To date, several authors suggest that oral vitamin B12 therapy remains one of "medicine's best kept secrets" [29].

However, it seems logical to differentiate two situations depending on the nature and the reversibility of the diagnosed FCM causes. In a recent work, Kaptan et al. showed that $H$. pylori eradication was sufficient to correct cobalamin deficiency [40]. The duration of cobalamin supplementation would correspond to the period of time required to treat the FCM cause, if the cause could be identified and effectively treated. If no effective treatment is possible, it would be difficult to withhold cobalamin supplementation, notably in the cases of idiopathic maldigestion or the intake of certain drugs that cannot be stopped and/or substituted [1]. In this context, the issue of poor longterm compliance needs to be emphasized: It is necessary to discuss with the patient the benefits and risks of oral administration, taking into account the particularities of each patient and his/her treatment adherence capacity $[1,41]$. In the event of poor compliance, standard parental treatment is efficacious. Potential allergies (in excipient not in vitamin himself) in the form of cutaneous reactions (rash, urticaria, rare Quincke's reaction...) to certain oral cobalamin preparations must also be considered. In our experience, oral cobalamin treatment avoids the discomfort, inconvenience and cost of monthly injections.

Vitamin B12 as oral cyanocobalamin is available in tablet forms and as drinkable vials of 250 à $1000 \mu \mathrm{g}$ [29], and is listed in the French Pharmacopeia and in Vidal with an authorized indication for conditions other than pernicious anaemia (preparations are not covered by Social Security, save IM and drinkable vials).

\section{Acknowlegments}

To professors Marc Imler and Jean-Louis Schlienger, who initiated the first research program on vitamin B12 in Strasbourg; to the clinicians who allowed the realisation of the clinical studies (CARE B12); and to the French Foundation for its support via the Robert Prize of 2004 and Jacqueline Zittoun, thanks to her knowledge of anaemia and vitamin B12 and folic acid metabolic abnormalities.

\section{References}

1. Matthews JH (1995) Cobalamin and folate deficiency in the elderly. Baillieres
Clin Haematol 8: 679-697.

2. Andrès E, Loukili NH, Noel E, Kaltenbach G, Abdelgheni MB, et al. (2004) Vitamin B12 (cobalamin) deficiency in elderly patients. CMAJ 171: 251-259.

3. Calabrino G, Peracchi M (2006) New insights into the pathophysiology of cobalamin deficiency. Trends Mol Med 12: 247-254.

4. Carmel R (1995) Malabsorption of food cobalamin. Baillieres Clin Haemato 8: 639-655.

5. Hvas AM, Nexo E (2006) Diagnosis and treatment of vitamin B12 deficiencyan update. Haematologica 91: 1506-1512.

6. Russel M (1992) Vitamin requirements in old age. Age Nutr 3: 20-23.

7. Dali-Youcef N, Andrès E (2009) An update on cobalamin deficiency in adults QJM 102: 17-28.

8. Doscherholmen A, Swain WR (1973) Impaired assimilation of egg Co57 vitamin B12 in patients with hypochlorhydria and after gastric resection. Gastroenterology 64: 913-919.

9. Dawson DW, Gozzard DI, Lewis MJ (1988) Protein-bound vitamin B12 absorption test. J Clin Pathol 41: 478-479.

10. Andrès E, Affenberger S, Vinzio S, Kurtz JE, Noel E, Kaltenbach G, et al. (2005) Food-cobalamin malabsorption in elderly patients: clinical manifestations and treatment. Am J Med 118: 1154-1159.

11. Lindenbaum J, Rosenberg IH, Wilson PW, Stabler SP, Allen RH (1994) Prevalence of cobalamin deficiency in the Framingham elderly population. Am J Clin Nutr 60: 2-11.

12. Van Asselt DZ, Blom HJ, Zuiderent R, Wevers RA, Jakobs C, et al. (2000) Clinical significance of low cobalamin levels in older hospital patients. Neth $J$ Med 57: 41-49.

13. Khanduri U, Sharma A, Joshi A (2005) Occult cobalamin and folate deficiency in Indians. Natl Med J India 18: 182-183.

14. Antony AC (2001) Prevalence of cobalamin (vitamin B-12) and folate deficiency in India-audi alteram partem. Am J Clin Nutr 74: 157-159.

15. Carmel R (1996) Subtle cobalamin deficiency. Ann Intern Med 124: 338-340.

16. Carmel R, Aurangzeb I, Qian D (2001) Associations of food-cobalamin malabsorption with ethnic origin, age, Helicobacter pylori infection, and serum markers of gastritis. Am J Gastroenterol 96: 63-70.

17. Koury MJ, Ponka P (2004) New insights into erythropoiesis: the roles of folate,vitamin B12, andiron. Annu Rev Nutr 24:105-131.

18. Andrès E, Perrin AE, Demangeat C, Kurtz JE, Vinzio S, et al. (2003) The syndrome of food-cobalamin malabsorption revisited in a Department of Internal Medicine. A monocentric cohort study of 80 patients. Eur J Intern Med 14: 221-226. 
Citation: Andres E, Serraj K, Mecili M, Kaltenbach G, Vogel T (2010) The Syndrome of Food-Cobalamin Malabsorption: A Personal View in a Perspective of Clinical Practice. J Blood Disord Transfus 2:108. doi:10.4172/2155-9864.1000108

Page 5 of 5

19. Jolobe OM (2007) Current haematological findings in cobalamin deficiency. Int J Lab Hematol 29: 73-74

20. Andrès E, Affenberger S, Federici L, Korganow AS (2006) Pseudo-thrombotic microangiopathy related to cobalamin deficiency. Am J Med 119: e3.

21. Andrès E, Noel E, Maloisel F (2003) Hematological findings in patients with food-cobalamin malabsorption. Am J Med 115: 592.

22. Loukili NH, Zimmer J, Affenberger S, Maloisel F, Andrès E, et al. (2007) Manifestations hématologiques de la carence en vitamine B12: données personnelles et revue de la littérature. Rev Med Interne 28: 225-231.

23. Maamar M, Mezalek ZT, Harmouche H, Adnaoui M, Aouni M, et al. (2008) Contribution of spinal MRI for unsuspected cobalamin deficiency in isolated sub-acute combined degeneration. Eur J Intern Med 19: 143-145.

24. Wickramasinghe SN (2006) Diagnosis of megaloblastic anaemias. Blood Rev 20: 299-318.

25. Pruthi RK, Tefferi A (1994) Pernicious anemia revisited. Mayo Clin Proc 69 144-150.

26. Carmel R, Perez-Perez GI, Blaser MJ (1994) Helicobacter pylori infection and food-cobalamin malabsorption. Dig Dis Sci 39: 309-314.

27. Evrengul H, Tanriverdi H, Kuru O, Enli Y, Yuksel D, et al. (2007) Elevated homocysteine levels in patients with slow coronary flow: relationship with Helicobacter pylori infection. Helicobacter 12: 298-305.

28. Lane LA, Rojas-Fernandez C (2002) Treatment of vitamin B12 deficiency anemia: oral versus parenteral therapy. Ann Pharmacother 36: 1268-1272.

29. Andrès E, Fothergill H, Mecili M (2010) Efficacy of oral cobalamin (vitamin B12) therapy. Expert Opinion Pharmacother 11: 249-256.

30. Andrès E, Kaltenbach G, Noel E, Noblet-Dick M, Perrin AE, et al. (2003) Efficacy of short-term oral cobalamin therapy for the treatment of cobalamin deficiencies related to food-cobalamin malabsorption. A study of 30 patients. Clin Lab Haematol 25: 161-166.

31. Andrès E, Kurtz JE, Perrin AE, Maloisel F, Demangeat C, et al. (2001) Oral cobalamin therapy for the treatment of patients with food-cobalamin malabsorption. Am J Med 111:126-129.

32. Andrès $E$, Kaltenbach G, Noblet-Dick M, Noel E, Perrin AE, et al. (2006) Hematological response to short-term oral cyanocobalamin therapy for the treatment of cobalamin deficiencies in elderly patients. J Nutr Health Aging 10: 3-6.

33. Andrès E, Loukili NH, Noel E, Maloisel F, Vinzio S, et al. (2005) Oral cobalamin (daily dose of 1000ig) therapy for the treatment of patients with pernicious anemia. An open label study of 10 patients. Curr Ther Res 66: 13-22.

34. Mecili M, Ciobanu C, Boddi V, D'Elios MM, Andrès E, et al. (2010) Vitamine B12 administrée par voie orale. Efficacité et tolérance chez 31 patients avec une maladie de Biermer ou une maldigestion des cobalamines alimentaires. Presse Med 39: e273-e279.

35. Kuzminski AM, Del Giacco El, Allen RH, Stabler SP, Lindenbaum J (1998) Effective treatment of cobalamin deficiency with oral cobalamin. Blood 92 1191-1198.

36. Bolaman Z, Kadikoylu G, Yukselen V, Yavasoglu I, Barutca S, et al. (2003) Ora versus intramuscular cobalamin treatment in megaloblastic anemia: a singlecenter, prospective, randomized, open-label study. Clin Ther 25: 3124-3134.

37. Slot WB, Merkus FW, Van Deventer SJ, Tytgat GN (1997) Normalization of plasma vitamin B12 concentration by intranasal hydroxocobalamin in vitamin B12-deficient patients. Gastroenterology 113: 430-433.

38. Carmel R (2000) Current concepts in cobalamin deficiency. Annu Rev Med 51 357-375.

39. Blacher J, Czernichow S, Raphae M, Roussel C, Chadefaux-Vekemans B, et al. (2007) Very Low Oral Doses of Vitamin B-12 Increase Serum Concentrations in Elderly Subjects with Food-Bound Vitamin B-12 Malabsorption. J Nutr 137 373-378.

40. Kaptan K, Beyan C, Ural AU, Cetin T, Avcu F, et al. (2000) Helicobacter pylor - Is it a novel causative agent in Vitamin B12 deficiency? Arch Intern Med160: 1349-1353.

41. Butler CC, Vidal-Alaball J, Cannings-John R, McCaddon A, Hood K, et al. (2006) Oral vitamin B12 versus intramuscular vitamin B12 for vitamin B12 deficiency : a systematic review of randomized controlled trials. Fam Pract 23: 279-285. 